\title{
In-vivo Protection from SARS-CoV-2 infection by ATN-161 in k18-hACE2 transgenic mice
}

Narayanappa Amruta ${ }^{a}$, Elizabeth B. Engler-Chiurazzi ${ }^{\mathrm{ab}}$, Isabel C. Murray-Brown ${ }^{\mathrm{a}}$, Timothy E. Gressett $^{\mathrm{a}}$, Ifechukwude J. Biose ${ }^{\mathrm{a}}$, Wesley H. Chastain ${ }^{\mathrm{a}}$, Gregory Bix, ${ }^{\text {abcde } \square}$

a Department of Neurosurgery, Clinical Neuroscience Research Center, Tulane University School of Medicine, New Orleans, LA 70112, USA

b Tulane Brain Institute, Tulane University, New Orleans, LA 70112, USA

c Department of Neurology, Tulane University School of Medicine, New Orleans, LA 70112, USA

d Department of Microbiology and Immunology, Tulane University School of Medicine, New Orleans, LA 70112, USA

e Tulane University School of Public Health and Tropical Medicine, New Orleans, LA 70122

\section{Correspondence:}

\section{Gregory Bix, M.D., Ph.D., F.A.H.A.}

Tulane University School of Medicine

Center for Clinical Neurosciences

131 S. Robertson, Ste 1300

Room 1349

New Orleans, LA 70112

e-mail: gbix@tulane.edu 


\begin{abstract}
Severe acute respiratory syndrome coronavirus 2 (SARS-CoV-2) is an infectious disease that has spread worldwide. Current treatments are limited in both availability and efficacy, such that improving our understanding of the factors that facilitate infection is urgently needed to more effectively treat infected individuals and to curb the pandemic. We and others have previously demonstrated the significance of interactions between the SARS-CoV-2 spike protein, integrin $\alpha 5 \beta 1$, and human ACE2 to facilitate viral entry into host cells in vitro. We previously found that inhibition of integrin $\alpha 5 \beta 1$ by the clinically validated small peptide ATN-161 inhibits these spike protein interactions and cell infection in vitro. In continuation with our previous findings, here we have further evaluated the therapeutic potential of ATN-161 on SARS-CoV-2 infection in k18-hACE2 transgenic (SARS-CoV-2 susceptible) mice in vivo. We discovered that treatment with single- or repeated intravenous doses of ATN-161 (1 mg/kg) within 48 hours after intranasal inoculation with SARS-CoV-2 lead to a reduction of lung viral load, viral immunofluorescence and improved lung histology in a majority of mice 72 hours post-infection. Furthermore, ATN-161 reduced SARS-CoV-2-induced increased expression of lung integrin $\alpha 5$ and $\alpha \mathrm{v}$ (an $\alpha 5$-related integrin that has also been implicated in SARS-CoV-2 interactions) as well as the $\mathrm{C}-\mathrm{X}-\mathrm{C}$ motif chemokine ligand $10(\mathrm{Cxcl10})$, further supporting the potential involvement of these integrins, and the anti-inflammatory potential of ATN-161, respectively, in SARS-CoV2 infection. To the best of our knowledge, this is the first study demonstrating the potential therapeutic efficacy of targeting integrin $\alpha 5 \beta 1$ in SARS-CoV-2 infection in vivo and supports the development of ATN-161 as a novel SARS-CoV-2 therapy.
\end{abstract}




\section{Introduction}

Severe acute respiratory syndrome coronavirus 2 (SARS-CoV-2), the agent causative of coronavirus disease 2019 (COVID-19), is a highly transmissible respiratory pathogen in which an estimated $14 \%$ of all patients will develop serious conditions, with a subsequent mortality rate of $1.4-3.4 \%$ [1-3]. Several non-pharmacological interventions have been implemented to slow down the spread of SARS-CoV-2[4-7]. However, to date there is no universally agreed direct therapy available to treat COVID-19. It is important to study effective therapeutic targets focusing on disrupting aspects of the viral replication process, including SARS-CoV-2 host cell entry [8], which uses its spike proteins to bind to the angiotensin-converting enzyme 2 (hACE2) receptor on targeted cells to facilitate its entry and replication [9]. The virus infects the cells after the proteolytic cleavage of the spike protein by the transmembrane serine protease 2 (TMPRSS2) or Cathepsin B or L or FURIN is required for spike protein priming and virus infection [10].

Integrins are family of cell adhesion receptors that may play an important role in SARSCoV-2 host cell entry and infection due to the spike protein containing an integrin binding motif arginine-glycine-aspartate (RGD) sequence [11-14]. Integrins are composed of non-covalently linked $\alpha$ and $\beta$ subunits that recognize and bind to extracellular matrix (ECM) proteins and mediate cell survival, proliferation, differentiation, and migration [15-17]. Integrin dimers are expressed in most cells, including endothelial cells, and epithelial cells in the respiratory tract [18], and are known to be involved in the infectious etiology of other viruses such as human cytomegalovirus [19], Epstein-Barr virus [20], rotavirus [21], Kaposi's sarcoma-associated virus (HHV-8) [22] and Ebola [23]. Importantly, the $\beta 1$ family of integrins are closely associated with ACE2 [24]. A recent study reviewed novel mutation (K403R) in the spike protein that does not exist in other strains of the coronavirus, creating an RGD motif, which could be recognized by integrins [2]. Therefore, the new RGD motif in SARS-CoV-2 could increase the binding potency of ACE2-positive target cells in association with $\beta 1$ integrins as well as potentially facilitating infection of ACE2-negative cells [2]. This could help explain the faster and aggressive spread of virus as compared to SARS-CoV-1, which belongs to the same family of betacoronaviruses [25]. Targeting therapies to disrupt the spike-binding event may also inhibit viral replication by halting host cell entry and offers a promising approach to treat COVID-19 [8]. 
Our laboratory has previously shown that the SARS-CoV-2 spike protein is capable of binding to $\alpha 5 \beta 1$ integrin in cell-free ELISA assays [26], an observation which has since been repeated in epithelial cell-containing systems in vitro [27]. We further demonstrated that the small pentapeptide $\alpha 5 \beta 1$ integrin inhibitor ATN-161 could inhibit this binding and also decrease SARS-CoV-2 infection and cytopathy in cultured vero-E6 cells [26]. ATN-161 has several properties that make it potentially attractive as a novel SARS-CoV-2 therapy; it is safe and welltolerated with no dose-limiting toxicity in phase I cancer clinical trials [28], has demonstrated invivo efficacy in mice against a different beta coronavirus, porcine hemagglutinating encephalomyelitis virus (PHEV) [29] as well as other disease/injury models[30, 31], and can also bind to and inhibit integrin $\alpha \mathrm{v} \beta 3$ which is similar to $\alpha 5 \beta 1$ integrin that has also been implicated in SARS-CoV-2 infection $[32,33]$. In the present study we examined the therapeutic potential of ATN-161 in a human ACE2 receptor-expressing K18 mouse model of SARS-CoV-2 infection.

\section{Methods}

\section{Mice and Ethics Statement}

Male heterozygous K18-hACE c57BL/6J mice (strain: 2B6.Cg-Tg(K18-ACE2)2Prlmn/J, 10weeks-old) were obtained from The Jackson Laboratory. Mice were housed in the animal facility at Tulane University School of Medicine. The Institutional Animal Care and Use Committee of Tulane University reviewed and approved all procedures for sample handling, inactivation, and removal from a BSL3 containment (permit number 3430 (\#5)).

\section{SARS-CoV-2 Infection}

Mice were inoculated with either saline or SARS-CoV-2 via intranasal administration by the ABSL3-trained staff with a dose of $2 \times 10^{5} \mathrm{TCID}_{50} /$ mouse to induce viral infection in these animals $[34,35]$. The infected mice were observed daily to record body weight and clinical signs of illness (e.g. fur ruffling, less activity). After 3 days post infection (dpi), the mice were euthanized by $\mathrm{CO} 2$ asphyxiation followed by cervical dislocation and lungs were harvested for histology, immunofluorescence and qRT-PCR analysis. 


\section{Treatment Interventions}

Mice received ATN-161 (1 mg/kg, Medkoo Biosciences, Morrisville, NC, USA) via retro orbital i.v. injections. The subjects were divided into 6 groups; two control groups were non-infected: 1. saline treated control (saline, $n=3$ ) and 2. ATN-161 treated mice (ATN-161, $n=3$ ). These mice resided in the BSL1 portion of the Tulane Department of Comparative Medicine animal housing facility. Four SARS-CoV-2 infected groups received either saline or ATN-161 prepared fresh daily (3. SARS-CoV-2 + saline $(n=5), 4$. SARS-CoV-2 + ATN-161 once at $2 \mathrm{~h}(\mathrm{n}=5)$, 5. SARSCoV-2 + ATN-161 daily (2, 24, and 48 h, $(\mathrm{n}=5))$ and 6. SARS-CoV-2 + ATN-161 once at $48 \mathrm{~h}$ $(n=5)$ treatment administration following intra nasal viral inoculation with SARS-CoV-2.

\section{Viral copy number determination}

Tissues were weighed and homogenized in Trizol Lysis Reagent (Invitrogen). RNA was extracted from lung homogenates according to the instructions of the RNA extraction kit manufacturer (RNeasy Plus Mini Kit; Qiagen) post phase separation using Trizol reagent. Total RNA (Five microliters) was added in duplicate to a 0.2-ml standard 96-well optical microtiter plate (Cat. No.N8010560; Thermo Fisher). qRT-PCR reaction was set by using TaqPath 1-Step Master Mix (Cat. No. A28527; Thermo Fisher) with a primers and a FAM-labeled probe targeting the N1 amplicon of N gene (2019-nCoV RUO Kit, Cat. No. 10006713; IDT-DNA) of SARS-CoV-2 (https://www.ncbi.nlm.nih.gov/nuccore; accession number MN908947), following the manufacturer's instructions. Viral load was calculated by the linear regression function by $\mathrm{Cq}$ values acquired from 2019 nCoV qRT-PCR Probe Assays. The viral copy numbers from the lung samples are represented as copies/100 ng of RNA as followed using a published assay [36, 34, 37]. Subgenomic mRNA (sgmRNA) encoding the E gene was quantified using FAM-labeled primers (sgm-N-for: 5'-CGATCTCTTGTAGATCTGTTCTC-3',sgm-N-Probe:5'FAMTAACCAGAATGGAGAACGCAGTGGG-TAMRA-3',sgm-N-reverse:5'-

GGTGAACCAAGACGCAGTAT-3'), following the manufacturer's instructions. Subgenomic N viral copy number was calculated by standard $\mathrm{Cq}$ values. The viral copy numbers from the lung samples are represented as copies/100ng of RNA followed using a published

assay $[37,34]$. 


\section{Gene expression}

The lung tissue was homogenized in Trizol Lysis Reagent (Invitrogen). RNA was extracted from lung homogenates according to the instructions of the RNA extraction kit manufacturer (RNeasy Plus Mini Kit; Qiagen) post phase separation using Trizol reagent. RNA was converted to cDNA using iScript reverse transcriptase master mix (Bio-Rad). qPCR was carried out with QuantStudio $\square 3$ Real-Time PCR Systems (Life Technologies) using TaqMan PCR Master Mix and premixed primers/probe sets (Thermo Fisher Scientific) sets specific for Itgav (Mm00434486_m1), Cxcl10 (Mm00445235_m1), Itga5 (Mm00439797_m1), Itgb3 (Mm00443980_m1), Itgb1 (Mm01253233_m1), ACE2 (Hs01085333_m1), and Hypoxanthine phosphoribosyltransferase, Hprt (Mm01545399_m1, Control gene) (Life Technologies) were used gene expression. Data were analyzed comparing control to SARS-CoV-2 infected mice and are presented as a fold change of control.

\section{Histology}

The harvested whole right lungs (three lobes) were fixed in Z-fix (Anatech Ltd, Battle Creek, MI, USA). Paraffin sections (5 $\mu \mathrm{m}$ in thickness) were used for haematoxylin and eosin and Masson's trichrome stains to identify morphological changes in lungs. Slides were imaged with a digital slide scanner (Zeiss Axio Scan; Zeiss, White Plains, NY). Representative photo micrographs at $20 \times$ magnification were acquired from the whole scanned right lung using the Aperio Image Scope software (version 12.3.2.8013, Leica, Buffalo Grove, IL, USA).

\section{SARS-CoV-2 immunofluorescence}

Fixed tissue samples were processed via indirect immunofluorescence assays (IFA) for the detection of the SARS-CoV-2 antigen. The slides were deparaffinized in xylenes and rehydrated through an ethanol series, followed by heat-induced antigen retrieval with high $\mathrm{pH}$ antigen unmasking EDTA solution. The slides were washed with PBS with $0.1 \%$ Triton X-100 and blocked with $10 \%$ normal goat serum at room temperaturefor $1 \mathrm{~h}$.Primary antibody (Polyclonal Anti-SARS Coronavirus (antiserum, Guinea Pig) 1:1000, NR-10361) incubation was achieved at room temperature for $1 \mathrm{~h}$. Slides were washed and primary antibody detected following $40 \mathrm{~min}$ incubation in an appropriate secondary antibody tagged with Alexa Fluor fluorochromes (1:1000) in normal goat serum. After washing in PBS, mounting media with DAPI was used to 
label the nuclei. Slides were imaged with a digital slide scanner (Zeiss Axio Scan.Z1; Zeiss, White Plains, NY). Fluorescent images were acquired using HALO (Indica Labs, v2.3.2089.70). Threshold and multiplex analyses were performed with HALO for quantitation.

\section{Statistics}

Statistical tests were performed with GraphPad Prism, 8.4.3 version (GraphPad Software, San Diego, CA). Data are presented as mean \pm SEM. Significant differences were designated using omnibus one-way ANOVA and, when significant, followed-up with two-group planned comparisons selected a priori to probe specific hypothesis-driven questions (saline vs SARSCoV-2+vehicle; SARS-CoV-2+vehicle vs each of the various SARS-CoV-2+ATN-161 treated groups); the Holm-Sidak adjustment was applied to control for multiple comparisons. Nonparametric tests were employed in the event of violations of underlying ANOVA assumptions. Statistical significance was taken at the $p<0.05$ level.

\section{Results}

ATN-161 impacts the Genomic-N and Sub genomic N (Sgm-N) viral load in SARS-CoV-2 infected K18-hACE2 mice lung tissue

Lung tissue expression of hACE2 and viral loads after 3dpi with SARS-CoV-2 + Saline or ATN-161 administered either once at $2 \mathrm{~h}$ or $48 \mathrm{~h}$ post-infection or daily, post-infection, were measured, analyzed and compared to Vehicle-treated/uninfected (no SARS-CoV-2 exposure) mice either given Saline or ATN-161 (daily) for 3dpi. (Fig 1A). For hACE2, the omnibus oneway ANOVA was not significant (Fig 1B).

For Genomic-N (Fig 1C), the omnibus one-way ANOVA was significant $[F(5,20)=12.84$, $p<0.0001]$. We followed up this significant analysis with two group planned comparisons using the Holm-Sidak correction. We found a significant increase in Genomic-N among SARS-CoV-2 + Saline mice compared to non-infected, Saline-treated mice $[t(6)=5.98, p<0.0001]$. Though we did not detect significant group differences between any other two-group comparison, visual inspection of the graph revealed that there was 1) heterogeneity among the ATN-161 treated groups, suggesting a dichotomy in this population with regards to response to the ATN-161 treatment with regard to the viral load and 2) a general trend towards reduced viral load among all ATN-161 treated groups, regardless of timepoint or number of injections. This indicated to us a potential for our analyses to be underpowered. Therefore, to increase power and reduce 
variability, we pooled all ATN-161 treated animals into a single group and re-analyzed the data by comparing lung viral load in this group to that of the SARS-CoV-2 + Saline-treated mice. We found a trend towards significance $[t(18)=2.03, p<0.06]$ such that ATN-161-treated mice had lower Genomic N viral load in lungs than SARS-CoV-2-infected mice. Then we analyzed the data using the Mann-Whitney $U$ nonparametric test to account for a significant $(p<0.01)$ violation of the homogeneity of variance assumption (though ANOVA is robust to this type of violation), the effect remained marginal $(p=0.08)$. We also dichotomized ATN-161-treated animals into 'responder' and 'non-responder' groups such that mice were considered nonresponders if they displayed Genomic $\mathrm{N}$ values $>2 \times 10^{9}$ (one power of 10 lower than the lowest value observed in the SARS-CoV-2 group), Sgm-N values > $1 \times 10^{5}$ (one power of 10 lower than the lowest value observed in the SARS-CoV-2 group), and viral immunohistology staining counts $>0.7$ (one power of 10 lower than the lowest value observed in the SARS-CoV-2 group). Ns of responders for each ATN-161 treated group were 3, 3, and 2 for ATN-161-2hr, ATN-161daily, and ATN-161-48hr groups respectively. When we re-analyzed the data by comparing lung viral load in these groups to that of the SARS-CoV-2 + Saline-treated mice, we found a significant omnibus one-way ANOVA $[F(2,17)=35.32, p<0.0001]$ such that ATN-161 responders had significantly lower genomic lung viral loads than SARS-CoV-2-infected animals $[t(17)=7.04, p<0.0001]$.

For Sgm-N (Fig 1D), the omnibus one-way ANOVA was significant $[F(5,20)=13.81$, $p<0.0001]$ such that there was a significant increase in Sgm-N among SARS-CoV-2 + Saline mice compared to non-infected, Saline-treated mice $[t(6)=6.13, p<0.0001]$. Analysis of Sgm-N values among pooled ATN-161-treated mice again revealed that ATN-161 reduced Sgm-N viral load $[t(18)=2.23, p<0.05]$ that persisted $(p=0.05)$ when the Mann-Whitney U non-parametric analysis was applied given the significant $(p<0.05)$ homogeneity of variance in this group. When we re-analyzed the data by comparing lung viral load in the responder/non-responder groups to that of the SARS-CoV-2 + Saline-treated mice, we found a significant omnibus one-way ANOVA $[F(2,17)=39.91, p<0.0001]$ such that ATN-161 responders had significantly lower Sgm-N lung viral loads than SARS-CoV-2-infected animals $[t(17)=7.40, p<0.0001]$. 


\section{ATN-161 effects on the expression of virus in SARS-CoV-2 infected K18-hACE2 mice lung} tissue.

Given the observations in Figure 1, we continued our analyses comparing non-infected Saline or ATN-161-treated mice with SARS-CoV-2+Saline and either pooled ATN-161-treated infected mice or ATN-161 responders/non-responders. Immunohistochemistry staining for SARS-CoV-2 positive cells was conducted on all mice. Representative SARS-CoV-2 viral staining images from saline/ATN-161 (i); SARS-CoV-2+vehicle (ii); Responders (iii) and Nonresponders (iv) with SARS-CoV-2+ATN-161 administration either 2, daily or $48 \mathrm{~h}$ administration, post SARS-CoV-2 intranasal inoculation are depicted in Fig 2A. All K-18 hACE2 mice infected with SARS-CoV-2 + Saline or non-responders from SARS-CoV-2+ATN161 administration group had multifocal regions of SARS-CoV-2-positive cells (ii, iv), whereas treatment with ATN-161, $2 \mathrm{~h}$ and daily administered groups show 3 mice are completely negative for SARS-CoV-2 protein and 2 mice are negative (responders) in 48h ATN-161 group out of 5 mice challenged for SARS-CoV-2.

One-way ANOVA of C-X-C motif chemokine ligand 10 (Cxcl10) mRNA expression in lung comparing saline or ATN-161 treated non-infected, SARS-CoV-2 + Saline, and SARSCoV-2 + ATN-161 pooled mice (Fig $2 \mathrm{~B}$ ) revealed a significant effect $[F(3,23)=4.56, p<0.05]$ such that SARS-CoV-2+Saline mice had significantly higher lung Cxcllo mRNA expression compared to Saline-treated uninfected mice $[t(6)=3.07, p<0.05]$ and pooled ATN-161-treated mice $[t(18)=2.46, p<0.05]$. One-way ANOVA of Cxcl10 mRNA expression in lung comparing saline or ATN-161 treated non-infected, SARS-CoV-2 + Saline, and SARS-CoV-2 + ATN-161 responders and non-responders (Fig 2C) revealed a significant effect $[F(4,21)=24.38, p<0.0001]$, that persisted when the Kruskal-Wallis non-parametric analysis $(p<0.005)$ was applied given the significant violation of homogeneity of variance $(p<0.05)$ in this ANOVA analysis. Two-group planned follow-up comparisons revealed that SARS-CoV-2+Saline mice had significantly higher lung $\mathrm{Cxcl10}$ mRNA expression compared to Saline-treated uninfected mice $[t(6)=5.59$, $p<0.0001]$ and ATN-161-treated responders $[t(11)=7.12, p<0.0001]$. 
Histopathological Analysis of SARS-CoV-2 infected K18-hACE2 mice lung tissue by Hematoxylin and eosin stain

Representative images of hematoxylin and eosin staining of lung sections from saline/ATN-161 (Fig. 3Ai-Aii); SARS-CoV-2+vehicle (Fig. 3Bi-ii); Responders (Fig. 3Ci-ii) and non-responders (Fig. 3Di-ii) with SARS-CoV-2+ATN-161 (either 2h, daily, or 48h) administration post-SARS-CoV-2 intranasal inoculation are shown in Figure 3. Histopathological observations indicated that multifocal lesion, moderate interstitial pneumonia (Fig. 3Bii, Dii, black frames), infiltration of lymphocytes (Fig. 3Bii, Dii, green arrow), fibrin exudation (Fig. 3Bii, black arrow) were observed in SARS-CoV-2+vehicle and SARS-CoV$2+\mathrm{ATN}-161$ non responders mice whereas these observations are less or completely absent in SARS-CoV-2+ATN-161 responders mice. Hematoxylin and eosin staining of lung sections from saline/ATN-161 (Fig. 3Ai-Aii) revealed no histopathological changes in any of the mice.

\section{Histopathological Analysis of SARS-CoV-2 infected K18-hACE2 mice lung tissue Masson's Trichrome stain}

Representative images of Masson's Trichrome-stained sections (Fig. 4Ai-Dii) of lung sections from saline/ATN-161 (Fig. 4Ai-Aii); SARS-CoV-2+vehicle (Fig. 4Bi-ii); Responders (Fig. 4Ci-ii) and Non-responders (Fig. 4Di-ii) with SARS-CoV-2+ATN-161 (either 2h, daily, or 48h) administration post SARS-CoV-2 intranasal inoculation. Histopathological analysis revealed multiple intra-arteriolar microthrombi (black arrows), intra-alveolar microthrombi (green arrows), large interstitial hemorrhagic area (yellow arrow) in SARS-CoV-2+vehicle and SARS-CoV-2+ATN-161 non responders mice whereas these observations are less or completely absent in SARS-CoV-2+ATN-161 responders mice. Masson's Trichrome staining of lung sections from saline/ATN-161 (Fig. 4Ai-Aii) were no histopathological changes in any of the mice.

Induced expression of integrin $\alpha 5$, and integrin $\alpha \mathrm{v}$ in the lungs of SARS-CoV-2 infected K18-hACE2 mice and is inhibited by ATN-161 treatment

One-way ANOVA of integrin- $\alpha 5$ expression in lung comparing saline or ATN-treated non-infected, SARS-CoV-2 + Saline, and SARS-CoV-2 + ATN-161 pooled mice was not significant (Fig 4A). One-way ANOVA of integrin- $\alpha 5$ expression in lung comparing saline or 
ATN-161 treated non-infected, SARS-CoV-2 + Saline, and SARS-CoV-2 + ATN-161 responders and non-responders (Fig 4B) revealed a significant effect $[F(4,21)=6.59, p<0.05]$, that persisted when the Kruskal-Wallis non-parametric analysis $(p<0.05)$ was applied given the trend towards a violation of homogeneity of variance in this ANOVA analysis $(p=0.06)$. Because there was very high variability in the SARS-CoV-2 + ATN-161 non-responders, and we were concerned about the possibility of inflated Type 1 error risk, we conservatively conducted two-group follow-up comparisons using the non-parametric approach (Dunn-corrected). We found that SARS-CoV-2+Saline mice tended to have higher lung integrin- $\alpha 5$ expression compared to uninfected Saline-treated mice $[z=2.32, p=0.06]$.

One-way ANOVA of integrin- $\alpha$ v expression in lung comparing saline or ATN-161 treated non-infected, SARS-CoV-2 + Saline, and SARS-CoV-2 + ATN-161 pooled mice was not significant (Fig 4C). One-way ANOVA of integrin- $\alpha \mathrm{v}$ expression in lung comparing saline or ATN-161 treated non-infected, SARS-CoV-2 + Saline, and SARS-CoV-2 + ATN-161 responders and non-responders (Fig 4D) revealed a significant effect $[F(4,21)=6.04, p<0.005]$, such that SARS-CoV-2+Saline mice had significantly higher lung integrin- $\alpha$ v expression compared to Saline-treated uninfected mice $[t(6)=2.70, p<0.05]$ and ATN-161-treated responders $[t(11)=2.67, p<0.05]$.

\section{Discussion}

The coronavirus disease-2019 (COVID-19) caused by SARS-CoV-2 continues to ravage the world. As of March 24, 2021, there were 3,089,162 deaths with a total of 145,759,060 confirmed (COVID-19) cases worldwide [38, 39]. While the development of vaccines and antibody treatments against COVID-19 is promising and globally accepted in the current pandemic [40], the emergence of SARS-CoV-2 viral variants may present major challenges to these therapeutic approaches. Like most viruses, SARS-CoV-2 mutates and continually presents variants. Spike protein mutations are the most common mutation seen in SARS-CoV-2 variants, which facilitate viral entry into the cell and mediate viral propagation by binding to ACE2 receptor. Interestingly, an RDG integrin-binding motif is a novel feature of SARS-CoV-2 spike protein, which is not seen in other coronaviruses $[41,11]$. While this feature may have enhanced viral infectivity of SARS-CoV-2, it remains unknown how variant strains of SARS-CoV-2 may affect binding to integrins, with the resultant feature of affecting viral entry and propagation. 
However, it is worth noting that to the best of our knowledge, none of the currently characterized SARS-CoV-2 variants have directly mutated the RGD motif; This suggests the possibility that the RGD motif is of evolutionary advantage to the virus by supporting its ability to infect hosts.

Integrins are cell surface receptors that may bind to the SARS-CoV-2 spike protein interaction $[42,43,11,33]$. In our previous study, we demonstrated by ELISA that the SARSCoV-2 spike protein and ACE2 could bind to $\alpha 5 \beta 1$, and that ATN-161 could disrupt both of these interactions [26]. We further demonstrated that ATN-161 could significantly reduce SARSCoV-2 infection (viral load, cell viability and cytopathy) in Vero (E6) cells in vitro [26]. In this study, we extend the understanding of the role of integrins and explored the therapeutic role of ATN-161 against SARS-CoV-2 infection in vivo in the k18-hACE2 mice model.

K18-hACE2 mice provide a platform for the rigorous screening of candidate drugs before their evaluation in other animal models [44]. This mouse model is widely used to evaluate the pathogenicity of viruses such as SARS-CoV-2 that require or prefer the human form of ACE2 (versus mouse ACE2) to readily infect mice and can be used to study potential therapies [45, 35]. Previous studies provided the evidence that SARS-CoV-2 infection could cause typical interstitial pneumonia and develop respiratory disease in hACE2-expressing mice resembling what is commonly seen in COVID-19 patients [46, 45, 47, 48].

We measured genomic-N (Nucleocapsid (N) protein) and Sgm-N in lungs to assess SARS-CoV-2viral infectivity and replication. Our results showed that SARS-CoV-2-infected hACE2 mice had significantly higher SARS-CoV-2 genomic-N. Similarly, viral sgmRNA copies were detected predominantly in the lung as compared to uninfected saline treated mice. SgmRNA levels of the virus is an adequate surrogate assay for detection of replicating virus (replicating virus separated from the total genome, and form dimers as the virus is replicating its machinery which can continue to produce protein) [34]. Thus, we are confident that our mice were successfully infected with SARS-CoV-2 [35].

We found that ATN-161-treated mice had lower Genomic-N viral load in lungs than saline treated SARS-CoV-2-infected mice. Visual inspection of Genomic-N and sgm-N graph revealed that there was 1) heterogeneity among the ATN-161 treated groups, suggesting a dichotomy in this population with regards to ATN-161 treatment response and viral load, and 2) a general trend towards reduced viral load among all ATN-161 treated groups, regardless of timepoint or number of injections. A limitation of this study is that it employed a limited number 
of K18 hACE2 mice, a function of the logistical difficulty of doing live virus BSL-3 studies. We also dichotomized ATN-161-treated animals into 'responder' and 'non-responder' groups such that mice were considered non-responders if they displayed Genomic N values $>2 \times 10^{9}, \mathrm{Sgm}-\mathrm{N}$ values $>1 \times 10^{5}$ and viral immunohistology staining counts $>0.7$ values observed in the SARSCoV-2 group in the SARS-CoV-2 + saline group. ATN-161 responders had significantly lower genomic lung viral loads than SARS-CoV-2-infected animals.

Accordingly, this bimodal distribution of responders may be due to our use of heterozygous (HT) K18-hACE2 mice, as the K18-hACE2 homozygous mouse model completely replaces mACE2 expression with hACE2 under the mAce2 promoter [49]. Thus, it might be possible that our use of HT K18-hACE2 mice in this study produced variable expression patterns of mACE2 vs hACE2, reducing the efficacy of ATN-161 in mice that expressed higher levels of mACE2 relative to hACE2. ATN-161 interference with mACE2- $\alpha 5 \beta 1$ interactions would presumably have minimal to no effect on SARS-CoV-2 infection as compared to impacting hACE2- $\alpha 5 \beta 1$ interactions. ATN-161 reduced Sgm-N viral load among pooled ATN-161-treated mice. When we re-analyzed the data by comparing lung viral load in the responder/nonresponder groups to that of the SARS-CoV-2 + Saline-treated mice, we found that ATN-161 responders had significantly lower Sgm-N lung viral loads than SARS-CoV-2-infected animals. This suggests a lack of statistical power due to low Ns among individual ATN-treated groups; follow-up studies with additional subjects will be conducted to replicate these findings.

All K-18 hACE2 mice infected with SARS-CoV-2 or non-responders from SARS-CoV2+ATN-161 administered group had multifocal regions of SARS-CoV-2-positive cells. Our results are further supported by recent findings of lung histological changes in SARS-CoV-2 infected hACE2 mice [35, 49]. Furthermore, we observed that viral immunohistology staining counts were negative in responders for each ATN-161 treated group with n's of 3, 3, and 2 for ATN-161-2 h, ATN-161-daily, and ATN-161-48 h groups, respectively. The infected K18hACE2 mice did not lose body weight after only 3dpi as expected, but we observed high levels of viral copies and infectious virus in the lungs given as demonstrated by other studies in K18hACE2 mice $[35,49,50]$.

In regards to an inflammatory response to SARS-CoV-2 infection, we observed that Cxcl10 mRNA expression was significantly upregulated in the lungs of SARS-CoV-2 infected mice as has previously been reported [50]. In patients having rapid early viral replication, this is 
followed by inflammatory responses that contribute to pathology [51]. Post-mortem analysis of human COVID-19 patients showed immune cell accumulation in the lungs [52]. In our study, ATN-161 treatment, either pooled or ATN-161 responders, significantly lowered SARS-CoV-2induced Cxcl10 levels, a particularly robust result suggesting that ATN-161 has antiinflammatory properties in the context of SARS-CoV-2 infection. This result is in agreement with our previous studies in experimental ischemic stroke where post-stroke treatment with ATN-161 reduced neuro-inflammation [31].

Morphological changes observed at 3 dpi in infected lungs of K18-hACE2 mice included multifocal lesions, moderate interstitial pneumonia, infiltration of lymphocytes, and fibrin exudation. These were seen in SARS-CoV-2+vehicle and SARS-CoV-2+ATN-161 non responders mice but were less or completely absent in SARS-CoV-2+ATN-161 responder mice as well as absent in uninfected saline/ATN-161 treated mice. These findings are consistent with previous reports from post-mortem examination of patients with COVID-19 and SARS-CoV-2infected K18-hACE2 mice in other reports [50, 49, 53-55].

Pulmonary fibrosis, a particularly negative consequence of COVID-19-induced acute respiratory distress syndrome [56], was not prominentin infiltrated areas at 3 dpi in infected lungs of K18-hACE2 mice. However, we observed moderate multiple intra-arteriolar microthrombi, intra-alveolar microthrombi, and large interstitial hemorrhagic areas in SARSCoV-2+vehicle and SARS-CoV-2+ATN-161 non responder mice whereas these observations were less or completely absent in SARS-CoV-2+ATN-161 responder mice. Severely infected COVID-19 patient autopsy samples showed that microthrombi or immunothrombi is associated with a hyperinflammatory response $[56,57]$. Our findings are further supported by recent results in the human immune system humanized mouse model on histological changes in the lungs with SARS-CoV-2 infection [58, 35, 49].

Our results suggest a critical role of integrins as an additional receptor to SARS-CoV-2 spike protein cell entry $[59,60]$. We observed induced expression of integrin $\alpha 5$ and integrin $\alpha \mathrm{v}$ in the lungs of SARS-CoV-2 infected K18-hACE2 mice whereas lung expression of hACE2 levels did not vary in SARS-CoV-2+Saline or ATN-161 treated mice, suggesting that SARSCoV-2 infection and / or pathogenesis involves these, and perhaps other integrins, that activate downstream signaling to induce lung pathology [33, 61, 62]. Indeed, a recent study showed that increased integrin $\alpha 5 \beta 1$ and $\alpha v \beta 3$ levels in cardiac myocytes, obtained from heart failure 
patients, correlates with ACE2 expression [63]. This suggests that the concomitant elevation of these integrins and the upregulation of ACE2 in an organ may render it more susceptible to SARS-CoV-2 infection. Hence, as observed in the present study, decreasing the expressions of $\alpha 5 \beta 1$ and $\alpha \mathrm{V} \beta 3$ in the presence of ACE2 may dampen the effect of SARS-CoV-2 infection on lung tissue morphology. Other studies have clearly linked integrin $\alpha 5 \beta 1$, and its inhibition, with other viral infections $[62,64]$. ATN-161 treatment inhibited porcine hemagglutinating encephalomyelitis virus (PHEV) infection and its increase in the expression of integrin $\alpha 5 \beta 1$ in vivo in a mouse model [64]. Similarly, we observed that ATN-161 treatment inhibits SARSCoV-2-induced integrin $\alpha 5$, and integrin $\alpha \mathrm{v}$ in the K18-hACE2 mice lungs among ATNresponders. Importantly, our studies were performed at the dose of ATN-161, $1 \mathrm{mg} / \mathrm{kg}$, that demonstrated efficacy in in vitro and in vivo preclinical studies in blocking angiogenesis, solid tumor growth, and ischemic stroke injury [65, 30,31]. This dose was also similar to the 0.8 $\mathrm{mg} / \mathrm{kg}$ dose used in the PHEV anti-viral in vivo studies [64]. However, as we and others have demonstrated U-shaped dose response effects with ATN-161 [30, 26] additional in vivo SARSCoV-2 dosing studies are necessary and currently underway. However, ATN-161 present several potential advantages as a novel COVID-19 therapy. Unlike other RGD-based peptides, it preferentially binds to and inhibits activated forms of $\alpha 5 \beta 1$ in areas of inflammation, hypoxia and angiogenesis [30]. ATN-161 also binds to integrin $\alpha v \beta 3$ [30], an additional integrin that has been implicated in SARS-CoV-2 pathogenesis [33, 32], and is safe, well-tolerated in human clinical trials (cancer) with no dose limiting toxicity $[28,66]$, and can be administered i.v., i.p., and intranasally [31, 67]; The latter may support a more readily accessible means of COVID-19 treatment as well as afford a prophylactic approach which is currently under investigation in our laboratory.

\section{Conclusion}

To the best of our knowledge, this study is the first to demonstrate that integrin blockade can reduce SARS-CoV-2 infection in vivo. Specifically, we demonstrated that post-infection treatment with ATN-161 reduces lung viral load, replication, improves lung histology and reduces lung $\alpha 5$ and $\alpha \mathrm{v}$ integrin expression in a majority of SARS-CoV-2 infected k-18 mice. Our results further support the hypothesis that integrins play an important role in SARS-CoV-2 
infection as well as support the further investigation of ATN-161, and potentially other antiintegrin agents, as novel therapies for COVID-19.

\section{Future perspective}

Although several studies have predicted the potential for SARS-CoV-2 to bind integrins and thereby infect host cells with or without associated ACE2 interaction, for the first time we present evidence here that inhibition of integrin $\alpha 5 \beta 1$ (and $\alpha \mathrm{v} \beta 3$ ) in vivo can reduce both SARSCoV-2 viral load and pathological complications in lung tissue of SARS-CoV-2 in k18-hACE2 mice. Despite the limitations of our study (small sample size, use of heterozygous k18-hACE2 mice), the promise for ATN-161 as a potential therapeutic and prophylaxis after SARS-CoV-2 exposure remains attractive. To date, several small-molecule drug and peptide treatments have been developed for intranasal delivery which reach systemic circulation rapidly, many of which have been formulated to treat diseases which have the ability to alter cognition, such as depression [68]. As the olfactory and trigeminal nerves offer a safe and effective delivery pathway to deliver therapeutic agents to the brain, an intranasal-based therapy to both prevent and treat neurological complications of post-acute COVID-19 syndrome may one day include a formulation of ATN-161 [69, 70].

AUTHOR CONTRIBUTIONS: N.A performed experiments, N.A, E.B.E-C, designed, analyzed the data, and wrote the manuscript. I.B.M., W.C. assisted in performing experiments. T.G., BIJ, performed literature searches and drafted discussion, and G.J.B. conceived, designed and supervised the experiments, and revised and finalized the manuscript. All authors have read and approved the final manuscript.

Acknowledgements: We would like to thank Drs. Jay K. Kolls, Xuebin Qin (Tulane University) for their thoughtful comments and advice on this manuscript. Angela Birnbaum, Kristin E. Chandler, Thompson, Carli C for BSL3 service (Tulane University). Authors are grateful to Naoki Iwanaga, Smither, Allison R, Brandon J. Beddingfield, Nicholas J. Maness for technical help in experiments. Authors are thankful to Cecily C. Midkiff, Confocal Microscopy and Molecular Pathology Core, Dina Guapp, Histology Core, Delucca, Beatris, Tulane University. The authors appreciate Rebecca Solch, Meshi Paz, Jaime Befeler, Hawkins, Scott V, Department of Neurosurgery at Tulane University, for assistance. 
Funding: Tulane University startup funds. to G.J.B and NIH/NIMH K01 MH117343 to E.B.EC.

Conflicts of Interest: The authors have declared that no conflict of interest exists.

\section{References}

1. Zhou F, Yu T, Du R, Fan G, Liu Y, Liu Z et al. Clinical course and risk factors for mortality of adult inpatients with COVID-19 in Wuhan, China: a retrospective cohort study. Lancet. 2020;395(10229):1054-62. doi:10.1016/S0140-6736(20)30566-3.

2. Carvacho I, Piesche M. RGD-binding integrins and TGF-beta in SARS-CoV-2 infections novel targets to treat COVID-19 patients? Clin Transl Immunology. 2021;10(3):e1240. doi:10.1002/cti2.1240.

3. Control CfD, Prevention. Interim clinical guidance for management of patients with confirmed coronavirus disease (COVID-19). 2020.

4. Perra N. Non-pharmaceutical interventions during the COVID-19 pandemic: A review. Phys Rep. 2021. doi:10.1016/j.physrep.2021.02.001.

5. Liu Y, Morgenstern C, Kelly J, Lowe R, Group CC-W, Jit M. The impact of nonpharmaceutical interventions on SARS-CoV-2 transmission across 130 countries and territories. BMC Med. 2021;19(1):40. doi:10.1186/s12916-020-01872-8.

6. Spinelli MA, Glidden DV, Gennatas ED, Bielecki M, Beyrer C, Rutherford G et al. Importance of non-pharmaceutical interventions in lowering the viral inoculum to reduce susceptibility to infection by SARS-CoV-2 and potentially disease severity. Lancet Infect Dis. 2021. doi:10.1016/S1473-3099(20)30982-8.

7. Eubank S, Eckstrand I, Lewis B, Venkatramanan S, Marathe M, Barrett CL. Commentary on Ferguson, et al., "Impact of Non-pharmaceutical Interventions (NPIs) to Reduce COVID-19 Mortality and Healthcare Demand". Bull Math Biol. 2020;82(4):52. doi:10.1007/s11538-02000726-x.

8. Xia S, Liu M, Wang C, Xu W, Lan Q, Feng S et al. Inhibition of SARS-CoV-2 (previously 2019-nCoV) infection by a highly potent pan-coronavirus fusion inhibitor targeting its spike protein that harbors a high capacity to mediate membrane fusion. Cell Res. 2020;30(4):343-55. doi:10.1038/s41422-020-0305-x.

9. Lan J, Ge J, Yu J, Shan S, Zhou H, Fan S et al. Structure of the SARS-CoV-2 spike receptorbinding domain bound to the ACE2 receptor. Nature. 2020;581(7807):215-20. doi:10.1038/s41586-020-2180-5.

10. Hoffmann M, Kleine-Weber H, Schroeder S, Kruger N, Herrler T, Erichsen S et al. SARSCoV-2 Cell Entry Depends on ACE2 and TMPRSS2 and Is Blocked by a Clinically Proven Protease Inhibitor. Cell. 2020;181(2):271-80 e8. doi:10.1016/j.cell.2020.02.052.

11. Sigrist CJ, Bridge A, Le Mercier P. A potential role for integrins in host cell entry by SARSCoV-2. Antiviral Res. 2020;177:104759. doi:10.1016/j.antiviral.2020.104759.

12. Yan S, Sun H, Bu X, Wan G. New Strategy for COVID-19: An Evolutionary Role for RGD Motif in SARS-CoV-2 and Potential Inhibitors for Virus Infection. Front Pharmacol. 2020;11:912. doi:10.3389/fphar.2020.00912.

13. Tresoldi I, Sangiuolo CF, Manzari V, Modesti A. SARS-COV-2 and infectivity: Possible increase in infectivity associated to integrin motif expression. J Med Virol. 2020;92(10):1741-2. doi:10.1002/jmv.25831. 
14. Aguirre C, Meca-Lallana V, Barrios-Blandino A, Del Rio B, Vivancos J. Covid-19 in a patient with multiple sclerosis treated with natalizumab: May the blockade of integrins have a protective role? Mult Scler Relat Disord. 2020;44:102250. doi:10.1016/j.msard.2020.102250.

15. Lu X, Lu D, Scully M, Kakkar V. The role of integrins in cancer and the development of anti-integrin therapeutic agents for cancer therapy. Perspect Medicin Chem. 2008;2:57-73.

16. Amruta N, Rahman AA, Pinteaux E, Bix G. Neuroinflammation and fibrosis in stroke: The good, the bad and the ugly. J Neuroimmunol. 2020;346:577318. doi:10.1016/j.jneuroim.2020.577318.

17. Rahman AA, Amruta N, Pinteaux E, Bix GJ. Neurogenesis After Stroke: A Therapeutic Perspective. Transl Stroke Res. 2021;12(1):1-14. doi:10.1007/s12975-020-00841-w.

18. Ishibashi Y, Relman DA, Nishikawa A. Invasion of human respiratory epithelial cells by Bordetella pertussis: possible role for a filamentous hemagglutinin Arg-Gly-Asp sequence and alpha5beta1 integrin. Microb Pathog. 2001;30(5):279-88. doi:10.1006/mpat.2001.0432.

19. Feire AL, Koss H, Compton T. Cellular integrins function as entry receptors for human cytomegalovirus via a highly conserved disintegrin-like domain. Proc Natl Acad Sci U S A. 2004;101(43):15470-5. doi:10.1073/pnas.0406821101.

20. Xiao J, Palefsky JM, Herrera R, Berline J, Tugizov SM. The Epstein-Barr virus BMRF-2 protein facilitates virus attachment to oral epithelial cells. Virology. 2008;370(2):430-42. doi:10.1016/j.virol.2007.09.012.

21. Zarate S, Romero P, Espinosa R, Arias CF, Lopez S. VP7 mediates the interaction of rotaviruses with integrin alphavbeta3 through a novel integrin-binding site. J Virol. 2004;78(20):10839-47. doi:10.1128/JVI.78.20.10839-10847.2004.

22. Akula SM, Pramod NP, Wang FZ, Chandran B. Integrin alpha3beta1 (CD 49c/29) is a cellular receptor for Kaposi's sarcoma-associated herpesvirus (KSHV/HHV-8) entry into the target cells. Cell. 2002;108(3):407-19. doi:10.1016/s0092-8674(02)00628-1.

23. Gire SK, Goba A, Andersen KG, Sealfon RS, Park DJ, Kanneh L et al. Genomic surveillance elucidates Ebola virus origin and transmission during the 2014 outbreak. Science. 2014;345(6202):1369-72. doi:10.1126/science.1259657.

24. Clarke NE, Fisher MJ, Porter KE, Lambert DW, Turner AJ. Angiotensin converting enzyme (ACE) and ACE2 bind integrins and ACE2 regulates integrin signalling. PLoS One. 2012;7(4):e34747. doi:10.1371/journal.pone.0034747.

25. Chen B, Tian EK, He B, Tian L, Han R, Wang S et al. Overview of lethal human coronaviruses. Signal Transduct Target Ther. 2020;5(1):89. doi:10.1038/s41392-020-0190-2.

26. Beddingfield BJ, Iwanaga N, Chapagain PP, Zheng W, Roy CJ, Hu TY et al. The integrin binding peptide, ATN-161, as a novel therapy for SARS-CoV-2 infection. Basic to Translational Science. 2021;6(1):1-8.

27. Park EJ, Myint PK, Appiah MG, Darkwah S, Caidengbate S, Ito A et al. The Spike Glycoprotein of SARS-CoV-2 Binds to beta1 Integrins Expressed on the Surface of Lung Epithelial Cells. Viruses. 2021;13(4). doi:10.3390/v13040645.

28. Cianfrocca M, Kimmel K, Gallo J, Cardoso T, Brown M, Hudes G et al. Phase 1 trial of the antiangiogenic peptide ATN-161 (Ac-PHSCN-NH 2), a beta integrin antagonist, in patients with solid tumours. British journal of cancer. 2006;94(11):1621-6.

29. Lv X, Li Z, Guan J, Zhang J, Xu B, He W et al. ATN-161 reduces virus proliferation in PHEV-infected mice by inhibiting the integrin alpha5beta1-FAK signaling pathway. Vet Microbiol. 2019;233:147-53. doi:10.1016/j.vetmic.2019.04.029. 
30. Doñate F, Parry GC, Shaked Y, Hensley H, Guan X, Beck I et al. Pharmacology of the novel antiangiogenic peptide ATN-161 (Ac-PHSCN-NH2): observation of a U-shaped dose-response curve in several preclinical models of angiogenesis and tumor growth. Clinical Cancer Research. 2008;14(7):2137-44.

31. Edwards DN, Salmeron K, Lukins DE, Trout AL, Fraser JF, Bix GJ. Integrin alpha5beta1 inhibition by ATN-161 reduces neuroinflammation and is neuroprotective in ischemic stroke. J Cereb Blood Flow Metab. 2020;40(8):1695-708. doi:10.1177/0271678X19880161.

32. Kliche J, Kuss H, Ali M, Ivarsson Y. Cytoplasmic short linear motifs in ACE2 and integrin beta3 link SARS-CoV-2 host cell receptors to mediators of endocytosis and autophagy. Sci Signal. 2021;14(665). doi:10.1126/scisignal.abf1117.

33. Meszaros B, Samano-Sanchez H, Alvarado-Valverde J, Calyseva J, Martinez-Perez E, Alves $\mathrm{R}$ et al. Short linear motif candidates in the cell entry system used by SARS-CoV-2 and their potential therapeutic implications. Sci Signal. 2021;14(665). doi:10.1126/scisignal.abd0334.

34. Han K, Blair RV, Iwanaga N, Liu F, Russell-Lodrigue KE, Qin Z et al. Lung Expression of Human Angiotensin-Converting Enzyme 2 Sensitizes the Mouse to SARS-CoV-2 Infection. Am J Respir Cell Mol Biol. 2021;64(1):79-88. doi:10.1165/rcmb.2020-0354OC.

35. Bao L, Deng W, Huang B, Gao H, Liu J, Ren L et al. The pathogenicity of SARS-CoV-2 in hACE2 transgenic mice. Nature. 2020;583(7818):830-3. doi:10.1038/s41586-020-2312-y.

36. Corman VM, Landt O, Kaiser M, Molenkamp R, Meijer A, Chu DK et al. Detection of 2019 novel coronavirus (2019-nCoV) by real-time RT-PCR. Euro Surveill. 2020;25(3). doi:10.2807/1560-7917.ES.2020.25.3.2000045.

37. Iwanaga N, Cooper L, Rong L, Beddingfield B, Crabtree J, Tripp RA et al. Novel ACE2IgG1 fusions with improved in vitro and in vivo activity against SARS-CoV2. bioRxiv. 2020.

38. https://www.who.int/emergencies/diseases/novel-coronavirus-2019 ACdC-pWHOA.

39. https://coronavirus.jhu.edu/map.html.

40. Ramanathan M, Ferguson ID, Miao W, Khavari PA. SARS-CoV-2 B.1.1.7 and B.1.351 Spike variants bind human ACE2 with increased affinity. bioRxiv. 2021. doi:10.1101/2021.02.22.432359.

41. Laha S, Chakraborty J, Das S, Manna SK, Biswas S, Chatterjee R. Characterizations of SARS-CoV-2 mutational profile, spike protein stability and viral transmission. Infect Genet Evol. 2020;85:104445. doi:10.1016/j.meegid.2020.104445.

42. Stewart PL, Nemerow GR. Cell integrins: commonly used receptors for diverse viral pathogens. Trends in microbiology. 2007;15(11):500-7.

43. Montagutelli X, Prot M, Levillayer L, Salazar EB, Jouvion G, Conquet L et al. The B1. 351 and P. 1 variants extend SARS-CoV-2 host range to mice. bioRxiv. 2021.

44. Golden JW, Cline CR, Zeng X, Garrison AR, Carey BD, Mucker EM et al. Human angiotensin-converting enzyme 2 transgenic mice infected with SARS-CoV-2 develop severe and fatal respiratory disease. JCI Insight. 2020;5(19). doi:10.1172/jci.insight.142032.

45. Jiang RD, Liu MQ, Chen Y, Shan C, Zhou YW, Shen XR et al. Pathogenesis of SARS-CoV2 in Transgenic Mice Expressing Human Angiotensin-Converting Enzyme 2. Cell. 2020;182(1):50-8 e8. doi:10.1016/j.cell.2020.05.027.

46. Guan W-j, Ni Z-y, Hu Y, Liang W-h, Ou C-q, He J-x et al. Clinical characteristics of coronavirus disease 2019 in China. New England journal of medicine. 2020;382(18):1708-20.

47. Huang C, Huang L, Wang Y, Li X, Ren L, Gu X et al. 6-month consequences of COVID-19 in patients discharged from hospital: a cohort study. Lancet. 2021;397(10270):220-32. doi:10.1016/S0140-6736(20)32656-8. 
48. Yinda CK, Port JR, Bushmaker T, Owusu IO, Avanzato VA, Fischer RJ et al. K18-hACE2 mice develop respiratory disease resembling severe COVID-19. bioRxiv. 2020. doi:10.1101/2020.08.11.246314.

49. Sun SH, Chen Q, Gu HJ, Yang G, Wang YX, Huang XY et al. A Mouse Model of SARSCoV-2 Infection and Pathogenesis. Cell Host Microbe. 2020;28(1):124-33 e4. doi:10.1016/j.chom.2020.05.020.

50. Winkler ES, Bailey AL, Kafai NM, Nair S, McCune BT, Yu J et al. SARS-CoV-2 infection of human ACE2-transgenic mice causes severe lung inflammation and impaired function. Nat Immunol. 2020;21(11):1327-35. doi:10.1038/s41590-020-0778-2.

51. Pan F, Ye T, Sun P, Gui S, Liang B, Li L et al. Time course of lung changes at chest CT during recovery from coronavirus disease 2019 (COVID-19). Radiology. 2020;295(3):715-21.

52. Xu Z, Shi L, Wang Y, Zhang J, Huang L, Zhang C et al. Pathological findings of COVID-19 associated with acute respiratory distress syndrome. Lancet Respir Med. 2020;8(4):420-2. doi:10.1016/S2213-2600(20)30076-X.

53. Tian S, Hu W, Niu L, Liu H, Xu H, Xiao SY. Pulmonary Pathology of Early-Phase 2019 Novel Coronavirus (COVID-19) Pneumonia in Two Patients With Lung Cancer. J Thorac Oncol. 2020;15(5):700-4. doi:10.1016/j.jtho.2020.02.010.

54. Schaller T, Hirschbuhl K, Burkhardt K, Braun G, Trepel M, Markl B et al. Postmortem Examination of Patients With COVID-19. JAMA. 2020;323(24):2518-20. doi:10.1001/jama.2020.8907.

55. Fox SE, Akmatbekov A, Harbert JL, Li G, Quincy Brown J, Vander Heide RS. Pulmonary and cardiac pathology in African American patients with COVID-19: an autopsy series from New Orleans. Lancet Respir Med. 2020;8(7):681-6. doi:10.1016/S2213-2600(20)30243-5.

56. Ackermann M, Verleden SE, Kuehnel M, Haverich A, Welte T, Laenger F et al. Pulmonary Vascular Endothelialitis, Thrombosis, and Angiogenesis in Covid-19. N Engl J Med. 2020;383(2):120-8. doi:10.1056/NEJMoa2015432.

57. Magro C, Mulvey JJ, Berlin D, Nuovo G, Salvatore S, Harp J et al. Complement associated microvascular injury and thrombosis in the pathogenesis of severe COVID-19 infection: A report of five cases. Transl Res. 2020;220:1-13. doi:10.1016/j.trsl.2020.04.007.

58. Brumeanu TD, Vir P, Shashikumar S, Karim AF, Kar S, Chung KK et al. A HumanImmune-System mouse model for COVID-19 research (DRAGA mouse: HLA-A2.HLADR4.Rag1KO.IL-2Rgammac KO.NOD). bioRxiv. 2020. doi:10.1101/2020.08.19.251249.

59. Kliche J, Kuss H, Ali M, Ivarsson Y. Cytoplasmic short linear motifs in ACE2 and integrin $\beta 3$ link SARS-CoV-2 host cell receptors to mediators of endocytosis and autophagy. Science Signaling. 2021;14(665).

60. Makowski L, Olson-Sidford W, W-Weisel J. Biological and clinical consequences of integrin binding via a rogue RGD motif in the SARS CoV-2 spike protein. Viruses. 2021;13(2):146.

61. Calver J, Joseph C, John A, Organ L, Fainberg H, Porte J et al. S31 The novel coronavirus SARS-CoV-2 binds RGD integrins and upregulates avb3 integrins in Covid-19 infected lungs. BMJ Publishing Group Ltd; 2021.

62. Hussein HA, Walker LR, Abdel-Raouf UM, Desouky SA, Montasser AKM, Akula SM. Beyond RGD: virus interactions with integrins. Archives of virology. 2015;160(11):2669-81.

63. Bristow MR, Zisman LS, Altman NL, Gilbert EM, Lowes BD, Minobe WA et al. Dynamic Regulation of SARS-Cov-2 Binding and Cell Entry Mechanisms in Remodeled Human Ventricular Myocardium. JACC Basic Transl Sci. 2020;5(9):871-83. doi:10.1016/j.jacbts.2020.06.007. 
64. Lv X, Li Z, Guan J, Hu S, Zhang J, Lan Y et al. Porcine Hemagglutinating Encephalomyelitis Virus Activation of the Integrin alpha5beta1-FAK-Cofilin Pathway Causes Cytoskeletal Rearrangement To Promote Its Invasion of N2a Cells. J Virol. 2019;93(5). doi:10.1128/JVI.01736-18.

65. Khalili P, Arakelian A, Chen G, Plunkett ML, Beck I, Parry GC et al. A non-RGD-based integrin binding peptide (ATN-161) blocks breast cancer growth and metastasis in vivo. Molecular cancer therapeutics. 2006;5(9):2271-80.

66. Cianfrocca ME, Kimmel KA, Gallo J, Cardoso T, Brown MM, Hudes G et al. Phase 1 trial of the antiangiogenic peptide ATN-161 (Ac-PHSCN-NH(2)), a beta integrin antagonist, in patients with solid tumours. Br J Cancer. 2006;94(11):1621-6. doi:10.1038/sj.bjc.6603171.

67. Sundaram A, Chen C, Khalifeh-Soltani A, Atakilit A, Ren X, Qiu W et al. Targeting integrin alpha5beta1 ameliorates severe airway hyperresponsiveness in experimental asthma. J Clin Invest. 2017;127(1):365-74. doi:10.1172/JCI88555.

68. Xu J, Tao J, Wang J. Design and Application in Delivery System of Intranasal Antidepressants. Front Bioeng Biotechnol. 2020;8:626882. doi:10.3389/fbioe.2020.626882.

69. Fortuna A, Alves G, Serralheiro A, Sousa J, Falcao A. Intranasal delivery of systemic-acting drugs: small-molecules and biomacromolecules. Eur J Pharm Biopharm. 2014;88(1):8-27. doi:10.1016/j.ejpb.2014.03.004.

70. Homayun B, Lin X, Choi HJ. Challenges and Recent Progress in Oral Drug Delivery $\begin{array}{llll}\text { Systems } & \text { for } \quad \text { Biopharmaceuticals. } & \text { Pharmaceutics. }\end{array}$ doi:10.3390/pharmaceutics11030129.

\section{Figure legends}

Figure 1. ATN-161 reduces the Genomic-N and Sub genomic $N(S g m-N)$ viral load in SARS-CoV-2 infected K18-hACE2 mice lung tissue

Schematic overview of experimental timeline for K18-hACE2 mice (A) 10-week old male K18hACE2 transgenic mice administered saline (black bar) or ATN-161 (1 mg/kg, blue bar) intravenously (via retro-orbital). Mice were inoculated via the intranasal route with Severe acute respiratory syndrome coronavirus 2 (SARS-CoV-2) $\left(2 \times 10^{5}\right.$ TCID50) + Saline (i.v. by retroorbital rout) (Red bar). ATN-161 (1 mg/Kg) treatment was administered at 3 different time periods, SARS-CoV-2+ATN-161-2h post infection (purple bar), SARS-CoV-2+ATN-161-daily $(2 \mathrm{~h}, 24 \mathrm{~h}$ and $48 \mathrm{~h}$ ) administration (orange bar), and SARS-CoV-2+ATN-161-48 h administration (green bar) post SARS-CoV-2 intranasal inoculation. Figure B, C, and D top inserts with brown bar represents SARS-CoV-2+ATN-161 all treatment groups pooled data; figure $\mathrm{B}, \mathrm{C}$, and $\mathrm{D}$ bottom insert with pink bar represents responding mice and light green bar represents non responding with SARS-CoV-2+ATN-161 (either 2, daily or 48h) treatment. 3 days post infection ( $3 \mathrm{dpi}$ ) the mice were euthanized, and RNA isolated from the left lungs by Trizol method for qRT-PCR (B) hACE2 expression in lungs of K18-hACE2 mice (C) viral genomic-N (Total-N) and (D) sub genomic-N mRNA (sgm-N). Experimental groups are divided into 6 groups. saline $n=3$; ATN-161 $n=3$; SARS-CoV-2 $(5$ mice for vehicle, 5 mice for each 3 ATN-161 groups). Data are presented as mean \pm SEM. P values represent saline vs SARS-CoV2+vehicle and SARS-CoV-2+vehicle vs SARS-CoV-2 +ATN-161 treatment groups.

Figure 2: ATN-161 reduces the expression of virus in SARS-CoV-2 infected K18-hACE2 mice lung tissue. Immunohistochemistry staining for SARS-CoV-2 (Ai-iv, orange arrowheads 
indicates SARS-CoV-2 viral stain (green) positive cells). SARS-CoV-2 viral staining representative image from saline/ATN-161 (i); SARS-CoV-2+vehicle (ii); Responders (iii) and Non-responders (iv) with SARS-CoV-2+ATN-161 administration either 2, daily or $48 \mathrm{~h}$ administration, post SARS-CoV-2 intranasal inoculation. The tissue analysis at 3 dpi using the protocol described in Figure 1. All K-18 hACE2 mice infected with SARS-CoV-2 + Saline or non-responders from SARS-CoV-2+ATN-161 administration group with have multifocal regions of SARS-CoV-2-positive cells (ii, iv), whereas treatment with ATN-161, $2 \mathrm{~h}$ and daily administered groups show 3 mice are completely negative for SARS-CoV-2 protein and 2 mice are negative (responders) in 48h ATN-161 group out of 5 mice challenged for SARS-CoV-2. (BC) Cxcl10 mRNA expression in lung. Scale bars, $50 \mu \mathrm{m}$. Green = SARS-CoV-2; White = nuclei/DAPI; Red = empty/autofluorescence. Data are presented as mean \pm SEM. $\mathrm{P}$ values represent saline vs SARS-CoV-2+vehicle and SARS-CoV-2+vehicle vs SARS-CoV-2+ATN-161 pooled, SARS-CoV-2+ATN-161 responders, and SARS-CoV-2+ATN-161 non-responders.

Figure 3. Histopathological Analysis of SARS-CoV-2 infected K18-hACE2 mice lung tissue (Ai-Dii) Hematoxylin and eosin staining of lung sections from saline/ATN-161 (Ai-Aii); SARSCoV-2+vehicle (Bi-ii); Responders (Ci-ii) and Non-responders (Di-ii) with SARS-CoV-2+ATN161 (either $2 \mathrm{~h}$, daily, or $48 \mathrm{~h}$ ) administration post SARS-CoV-2 intranasal inoculation with tissue analysis at 3 dpi using the protocol described in Figure 1. Histopathological observations indicated that multifocal lesion, moderate interstitial pneumonia, (Bii, Dii, black frames), infiltration of lymphocytes (Bii, Dii, green arrow), fibrin exudation (Bii, black arrow). Each image is representative of a group of Control $n=3$; ATN-161 $n=3$; SARS-CoV-2 (5 mice for vehicle, 5 mice for each 3 ATN-161 groups). Scale bar: $500 \mu \mathrm{m}(\mathrm{Ai}, \mathrm{Bi}, \mathrm{Ci}$, and Di) and $200 \mu \mathrm{m}$ (Aii, Bii, Cii, and Dii).

Figure 4. Histopathological Analysis of SARS-CoV-2 infected K18-hACE2 mice lung tissue. Masson's Trichrome-stained sections (Ai-Dii) of lung sections from Saline/ATN-161 (Ai-Aii); SARS-CoV-2+vehicle (Bi-ii); Responders (Ci-ii) and Non-responders (Di-ii) with SARS-CoV2+ATN-161(either 2h, daily, or 48h) administration post SARS-CoV-2 intranasal inoculation with tissue analysis at 3 dpi using the protocol described in Figure 1. Histopathological observations indicated that showing multiple intra-arteriolar microthrombi (black arrows), intraalveolar microthrombi (green arrows), large interstitial hemorrhagic area (yellow arrow). Each image is representative of a group of Control $n=3$; ATN-161 $n=3$; SARS-CoV-2 (5 mice for vehicle, 5 mice for each 3 ATN-161 groups). Scale bar: $500 \mu \mathrm{m}(\mathrm{Ai}, \mathrm{Bi}, \mathrm{Ci}$, and Di) and $200 \mu \mathrm{m}$ (Aii, Bii, Cii, and Dii).

Figure 5. Induced expression of integrin $\alpha 5$, and integrin $\alpha \mathrm{v}$ in the lungs of SARS-CoV-2 infected K18-hACE2 mice and is inhibited by ATN-161 treatment. Integrin $\alpha 5$ (A-B), and Integrin $\alpha \mathrm{v}$ (C-D) mRNA expression in lung at different time periods of ATN-161 by intravenous injection (i.v) after infection with SARS-CoV-2 (TCID50 $=2 \times 10^{5} / 0.05 \mathrm{~mL}$ ) was determined by qRT-PCR. Data are presented as mean \pm SEM. P values represent saline vs SARS-CoV-2+vehicle and SARS-CoV-2+vehicle vs SARS-CoV-2+ATN-161 pooled, SARSCoV-2+ATN-161 responders, and SARS-CoV-2+ATN-161 non-responders. 
bioRxiv preprint doi: https://doi.org/10.1101/2021.05.08.443275; this version posted May 9, 2021. The copyright holder for this preprint (which was not certified by peer review) is the author/funder, who has granted bioRxiv a license to display the preprint in perpetuity. It is made available under aCC-BY-NC-ND 4.0 International license.

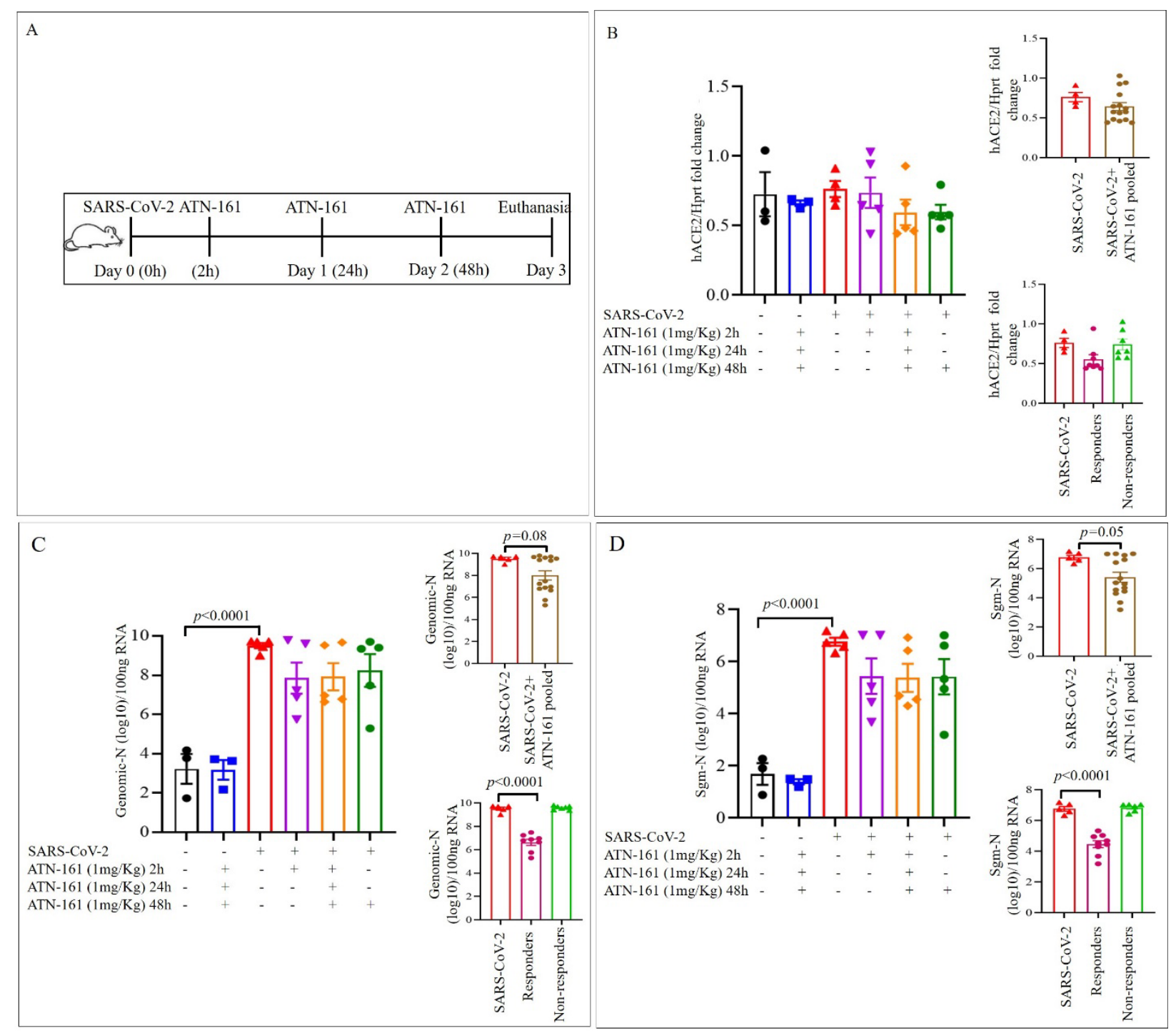

Figure 1. 
bioRxiv preprint doi: https://doi.org/10.1101/2021.05.08 443275; this version posted May 9,2021 . The copyright holder for this preprint (which was not certified by peer review) is the author/funder, who has granted bioRxiv a license to display the preprint in perpetuity. It is made available under aCC-BY-NC-ND 4.0 International license.

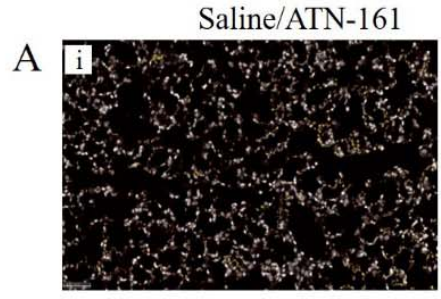

B
SARS-CoV-2+vehicle
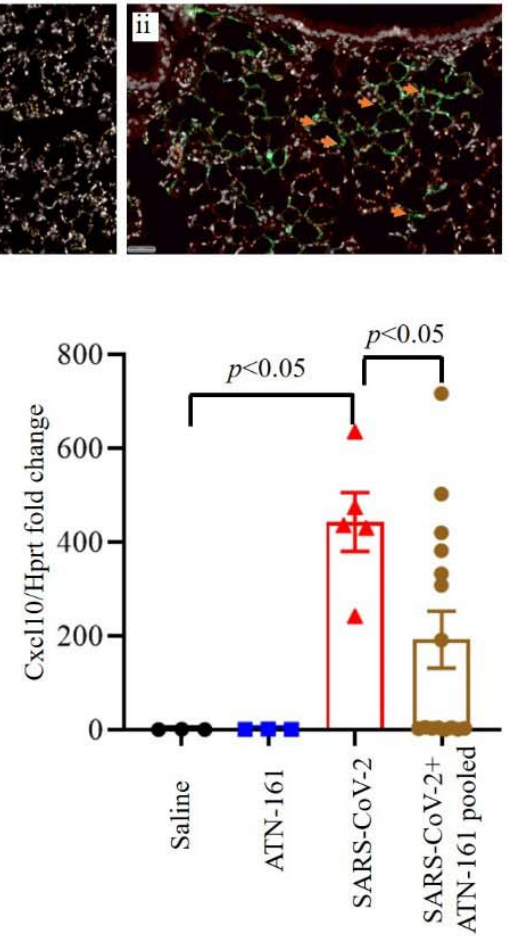

SARS-CoV-2+ATN-161

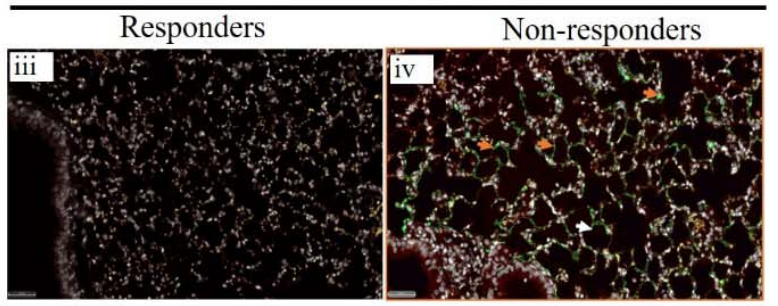

C

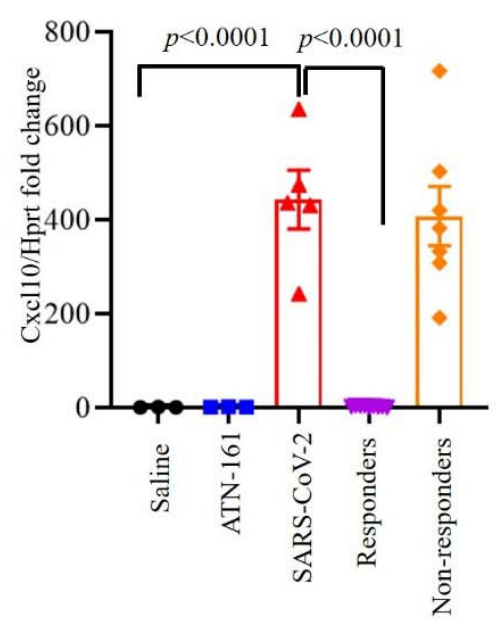

Figure 2.

Saline/ATN-161
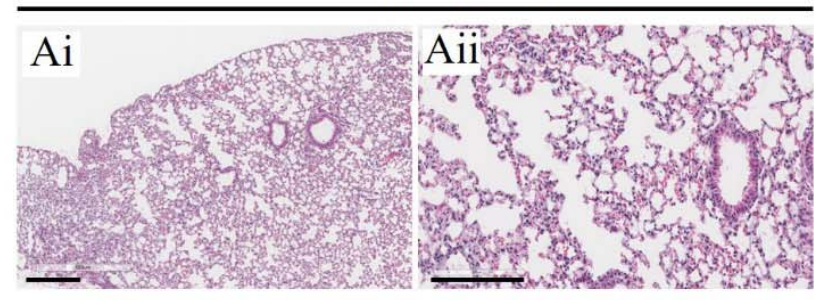

SARS-CoV-2+ATN-161

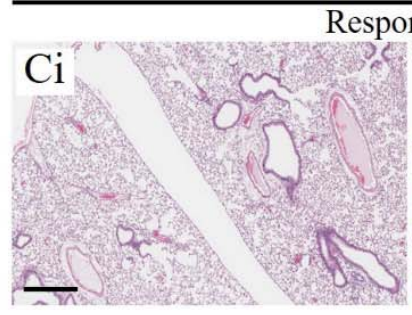

Responders
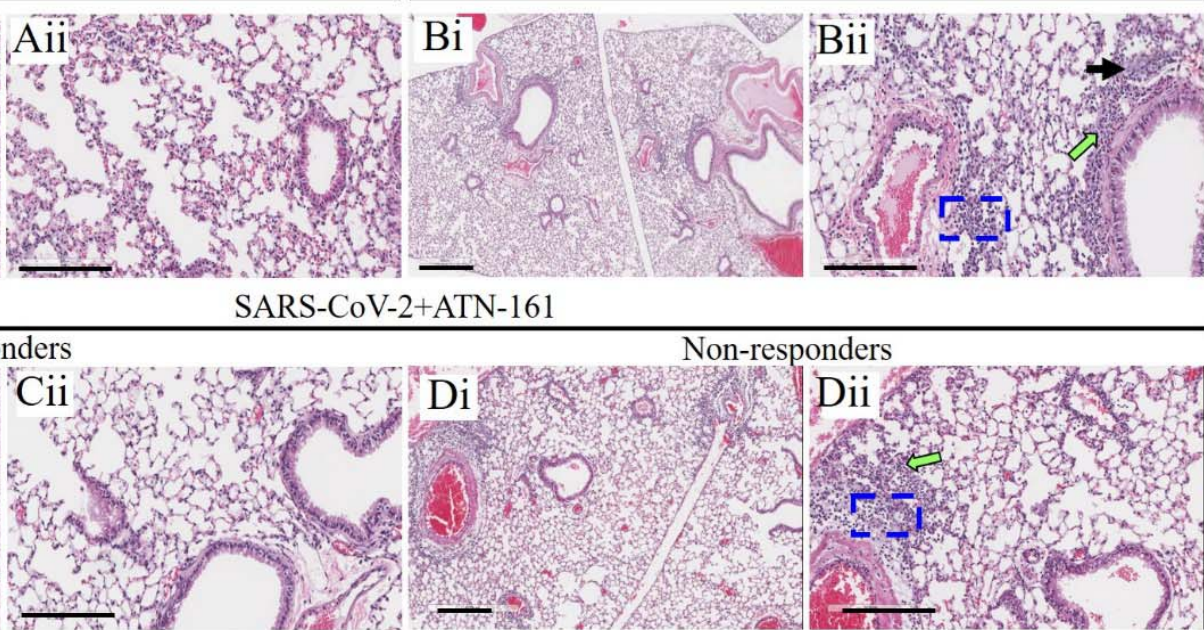

Non-responders

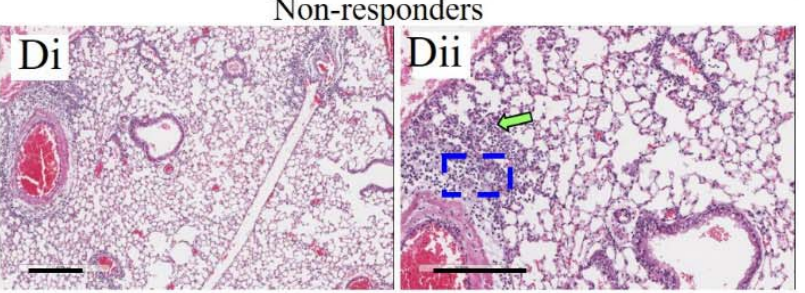

\section{Figure 3.}


bioRxiv preprint doi: https://doi.org/10.1101/2021.05.08.443275; this version posted May 9 2021. The copyright holder for this preprint (which was not certified by peer review) is the author/funder, who has granted bioRxiv a license to display the preprint in perpetuity. It is made available under aCC-BY-NC-ND 4.0 International license.

Saline/ATN-161

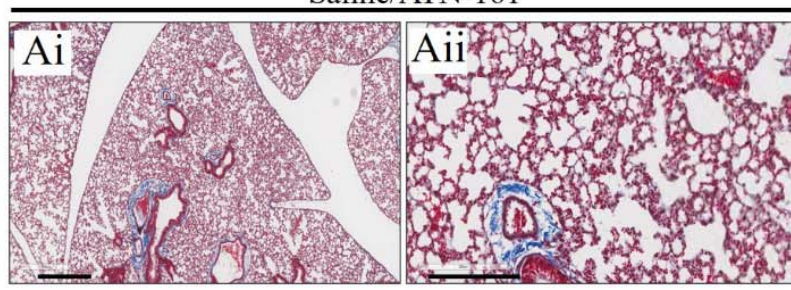

SARS-CoV-2+ATN-161
SARS-CoV-2+vehicle

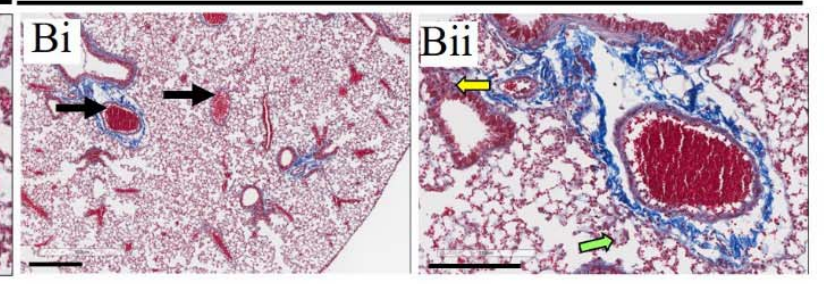

Non-responders

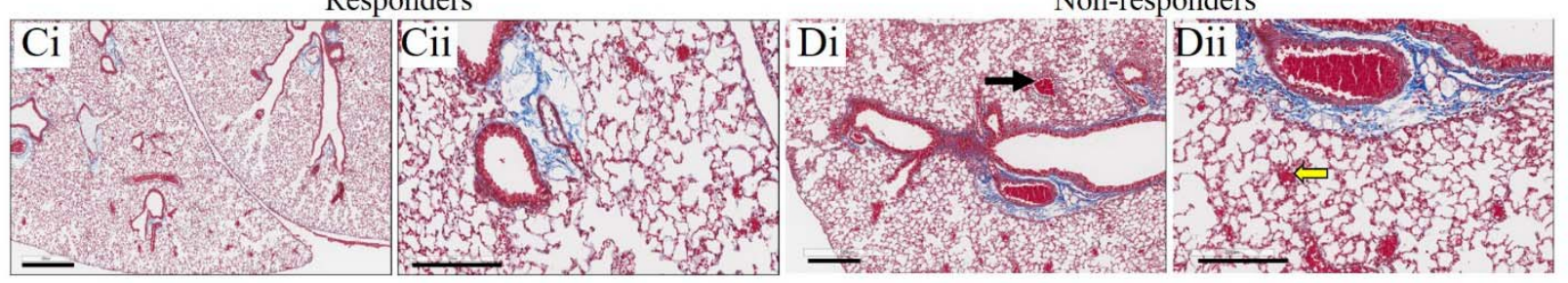

\section{Figure 4.}


A

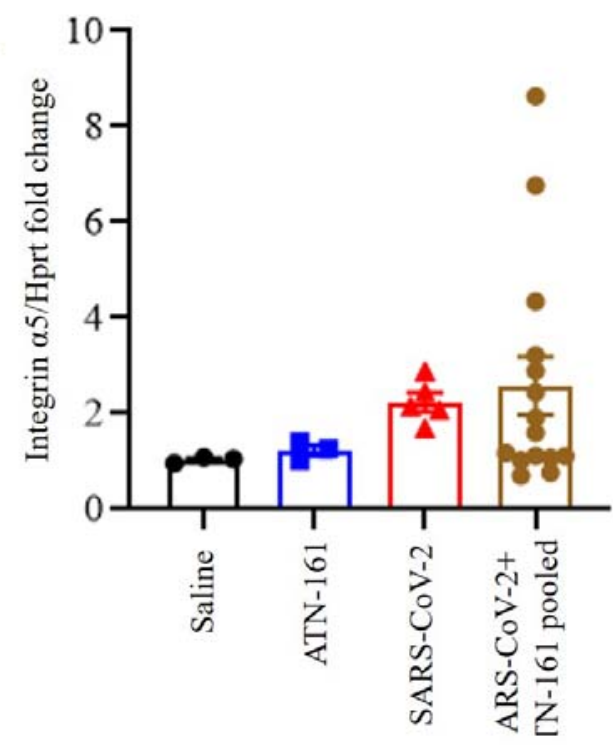

$\mathrm{C}$

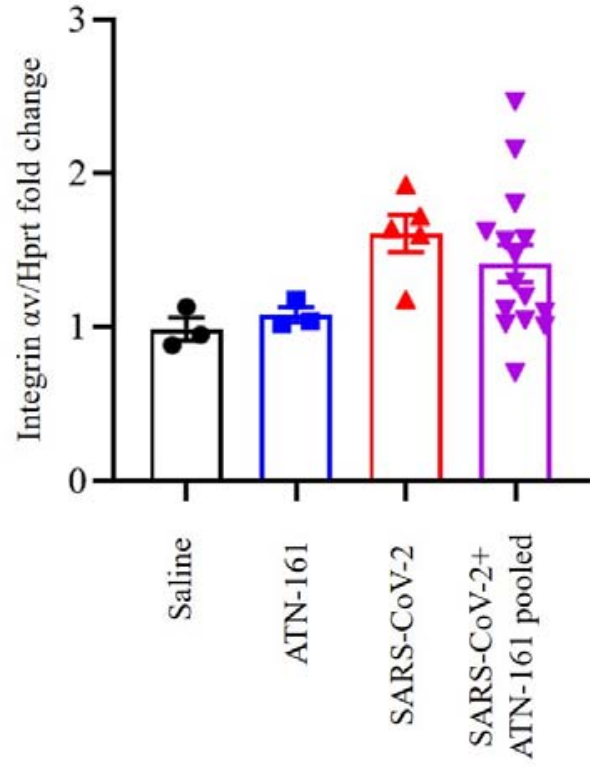

B

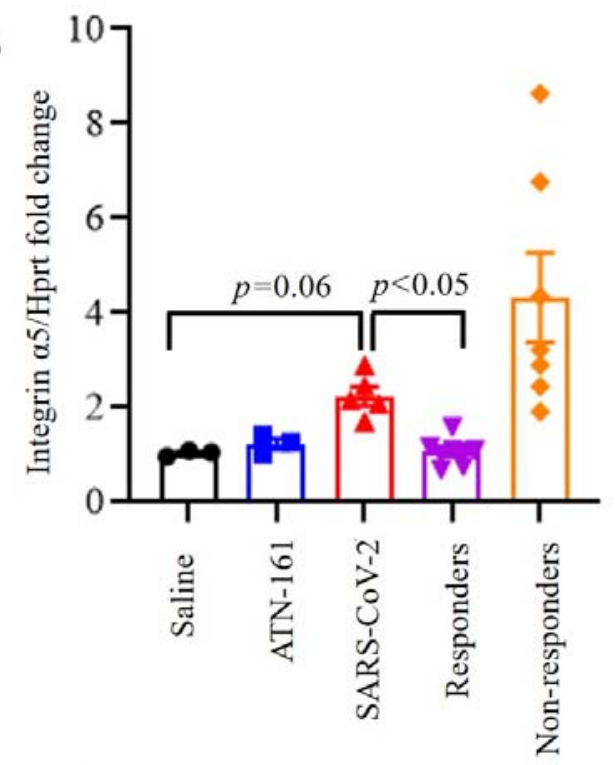

D

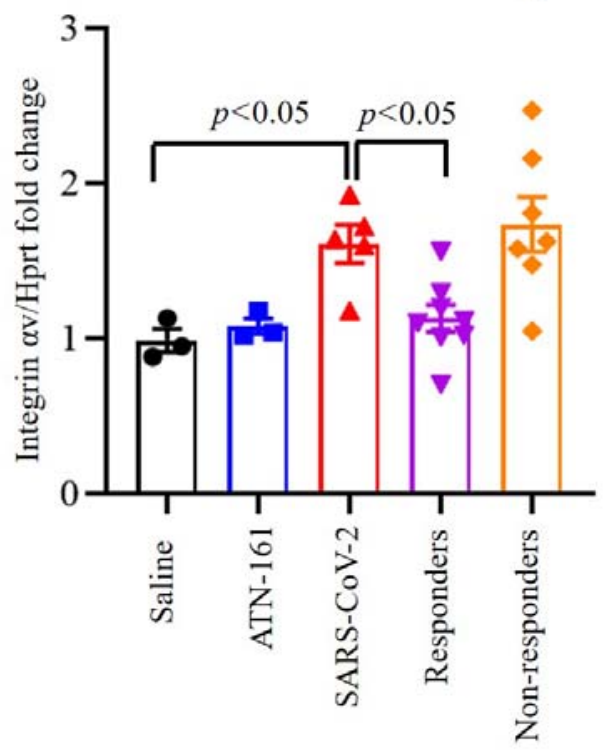

Figure 5. 